\title{
Virtual Reality: Is It Helping Children Cope with Fear and Pain During Vaccination?
}

\author{
Arwa Althumairi (ID \\ Maryam Sahwan \\ Sawsan Alsaleh \\ Zinab Alabduljobar \\ Duaa Aljabri (ID
}

Department of Health Information Management and Technology, College of Public Health, Imam Abdulrahman bin

Faisal University, Dammam, Saudi Arabia
Background: Virtual reality (VR) is an innovative distraction technology in health care, but little is known about this topic in Saudi Arabia. The aim of this study was to assess the effectiveness of using VR to reduce pain and fear among children during vaccination.

Methods: It is a cross-sectional study design. A total of 104 children (ages 4-6 years) receiving routine vaccinations in a single primary health care in Eastern Region, Saudi Arabia, participated in the study and grouped to a VR technology intervention group or vaccination as usual without VR distraction. The primary outcome is the difference in the child's self-rated fear and pain scores between those who have been vaccinated with or without VR distraction, measured by the two validated international facial expressions scales Wong-Baker FACES Pain Scale and Children's Fear Scale.

Results: In the two-month study period, 53 children were vaccinated using the VR technology and 50 children were vaccinated without VR. Bivariate analysis showed a significantly lower pain score among the VR group ( $\bar{x}=1.36$, SD 2.06) compared with the group without VR $(\bar{x}=6.90$, SD 3.47) (P-value $<0.001)$. Similarly, fear score was lower in the VR group $(\bar{x}=0.64$, SD 0.92) compared with the group without VR $(\bar{x}=2.88, \mathrm{SD} 1.55)(\mathrm{P}<0.001)$. In multivariable regression models adjusted for age and gender, children vaccinated using the VR technology had significantly lower pain and fear scores compared with those who were vaccinated as usual without VR distraction.

Conclusion: VR technology showed a positive impact on reducing pain and fear among children aged 4-6 years during vaccination. Policymakers are encouraged to expand the use of this distraction tool in primary health centers to improve the vaccination experience among children.

Keywords: vaccination, virtual reality, pain and fear

\section{Introduction}

Germs such as bacteria or viruses can invade and harm the human body, causing illnesses. This invasion is called an infection. The immune system uses several tools to defend itself against harmful germs. ${ }^{1}$ Over the years, vaccination has notably been an advanced external tool in helping the immune system to decrease infections that are associated with morbidity and mortality. ${ }^{2}$ According to the World Health Organization (WHO), vaccination prevents from 2 to 3 million deaths every year from infectious diseases. ${ }^{3}$ Moreover, the Centers for Disease Control and Prevention suggested that vaccination is the greatest public health achievement of the 20 th century. ${ }^{4}$

However, pain and fear related to vaccination are one of the most common burdens faced by children. ${ }^{5}$ Vaccination improves child health and
Correspondence: Arwa Althumairi Department of Health Information Management and Technology, College of Public Health, Imam Abdulrahman bin Faisal University, P.O.box 2954, Dammam, 6603-342II, Saudi Arabia

Tel +966 I3 3335213

Email aalthumairi@iau.edu.sa 
reduces mortality and morbidity rates. ${ }^{6}$ Despite this fact, the injection needle is still seen as painful and dreadful among many children during immunization. Therefore, healthcare professionals may ask parents for help to calm their child, or some parents may delay their child's appointment due to this discomfort process. ${ }^{5,7,8}$ To overcome pain perception and needles fear among children, several distraction techniques have been used as nonpharmacological interventions in the healthcare field. ${ }^{8}$

Distraction is a method of focusing children's attention on an alternative stimulus that is more engaging and enjoyable. It can help children to draw away pain and fear through engaging in other activities, whether cognitive or behavioral. Distraction techniques include internal (such as imaginary) or external; audio (such as music), visual (such as book), or audio-visual (such as movies). ${ }^{9}$ Moreover, recent studies have documented that engaging multiple senses, such as allowing a person to hear sounds and view visual images, is a more attractive technique in distracting children's pain and phobia perception, unlike with techniques that engage only one sense such as music. ${ }^{10}$ An example of a multi-sensory engaging technique is Virtual Reality (VR) distraction.

Virtual Reality is defined as "a computer technology that enables users to view or immerse themselves in an alternate world". ${ }^{11}$ To be more specific, it is a method through which people virtually isolate themselves from the real world through multisensory stimulation such as vision, hearing, and sometimes touch. ${ }^{10,12}$ Although VR has created a revolution in the gaming industry, its use has expanded to other areas such as health care. Different VR applications have been used in the hospital setting such as: Snow World, that explores an icy 3D world, involving throwing snowballs at snowmen and penguins; Gorilla Exhibit, that visits the gorilla habitat at the Zoo; Aqua, that explores and interacts with an underwater world; and Bear Blast, that shoots balls at animated teddy bears. Those applications have been used in paediatrics as distraction tools to reduce anxiety and pain while administering invasive medical procedures such as chemotherapy, physical therapy range of motion exercises for burn patients, burn wound cleaning, IV placements, and dental treatments. ${ }^{5,8,10-16,22-28}$

Further studies have proven the feasibility of VR for converting unpleasant emotional experiences into less distressing, potentially pain-free events among children ${ }^{5}$ who are exposed to needle procedures such as peripheral intravenous (IV), ${ }^{13}$ lumbar punctures or blood draws, ${ }^{14-17}$ and vaccinations. ${ }^{8,18}$

In Saudi Arabia, the Ministry of Health (MOH) has launched a Virtual Reality (VR) intervention program in selected Primary Care Centers (PHCs) around the country, as an initiative to decrease needle phobia and improve children's experience in routine vaccinations. ${ }^{7}$ It has been reported that up to $10 \%$ of the population avoid vaccination due to needle phobia. ${ }^{19}$ However, there were no reported outcomes in the study country on the effectiveness of the intervention on reducing pain and fear during vaccination. Hence, this paper is aimed to support the experience of VR glasses into academic research study in the Kingdom of Saudi Arabia, with the objective of assessing the differences in pain and fear scores between children's experience to virtual reality, compared with standard care vaccination between ages of 4-6 years. Our primary hypothesis is that participants who "go into" the computer-generated world during their vaccinations, will report significantly less fear and pain, compared to standard of care (No VR).

\section{Methodology}

A quantitative research cross-sectional method was conducted with a cross-sectional study at a primary healthcare centre (PHC) located in the Eastern Region of Saudi Arabia. The independent variables were age, gender and the vaccination technique (with or without using VR technology). The dependent variables were pain and fear scores.

\section{Study Participants}

A total of 104 children who accessed the Healthy Child and Vaccination Unit for vaccination during the twomonth study period (January and February 2019), and aged between 4-6 years old were included in the study as this was the age group commonly approved to wear the VR glasses. The clinic used the VR based on parent preference and children's acceptance to wear VR glasses, therefore the participant children were divided into two groups: children who used the VR during vaccination and children who did not use VR during vaccination based on the participant preference, not randomly allocated into groups.

\section{Description of the VR Intervention}

The audio-visual VR device (Future Sight All-in-One, Virtual Reality Headset, Grey, Melkco Inc.) involves 
wearing the VR headset and watching a two-minute 3D animated adventure story that has been created by the Innovative Centre of the $\mathrm{MOH}$. The nurse sees the story on a separate screen and the story actions are synchronized with the medical intervention such as settling the child arm, cleansing the skin and administering the injection.

\section{Data Collection Tools}

The information for the study was collected retrospectively after the vaccination was completed. A data collection form was created; this is divided into two sections. The first section is completed by the nurse responsible for the vaccination, it includes demographic characteristics of the child, age and gender, and if they used VR during vaccination. The second part is filled by the child to describe their pain and fear after vaccination. Once vaccination was completed, children were asked to fill a form to measure pain and fear levels through two international facial expressions scales. ${ }^{15,20}$ Pain was assessed using Wong-Baker FACES ${ }^{\circledR 21}$ Pain Rating Scale that includes face expressions arranged from 0 to 10 , where number 10 is classified as the worst pain with crying face. Fear was assessed using the McMurtry Children's Fear Scale, which includes 5 faces arranged from 0 to 4 , where number 4 was expressing the most scared feeling.

\section{Ethical Considerations}

This research study was approved by the Institutional Review Board of Imam Abdulrahman Bin Faisal University (No. IRB-UCS-2018-03-282). In addition, a written informed consent was signed and dated by parent or legal guardian according to local regulations. This study was conducted in accordance with the Declaration of Helsinki.

\section{Data Analysis}

Data analysis was performed using SPSS 24.0 software (SPSS Inc.). Analysis involved descriptive statistics, bivariate ( $t$ test and Mann-Whitney) and multivariate linear regression analysis. Categorical variables (gender, use of VR) were summarized and reported in terms of frequency and percentage. Continuous variables (age, pain score, fear score) were summarized and reported in terms of Mean \pm SD. Independent sample $t$-test was applied to compare means pain and fear score between gender and use of VR during vaccination. Pearson correlation test was applied to compare means between age and the outcome variables. Linear regression was applied to estimate the relationship between the technique of vaccination and the outcome variables adjusting for age and gender. The statistical significance was considered when p-value was less than 0.05 in $95 \%$ confidence interval.

\section{Results}

A total of 104 subjects were included in this study. The VR intervention group who received the VR distraction intervention prior to vaccine administration included 53 children (50.96\%), while the control group who received the vaccination without VR distraction included 51 children $(49.03 \%)$. Insignificant differences were found in gender and age across the two groups, indicating homogeneous samples ( $p$-value $>0.05$ ). Regarding our primary hypothesis, as predicted, the mean pain score was lower in the VR distraction group (1.36 \pm 2.067$)$ compared with the group without distraction $(6.90 \pm 3.471)$. In addition, fear mean score was lower in the VR distraction group (0.64 \pm 0.922) compared with the group without distraction (2.88 \pm 1.558 ) (Table 1). The outcome variable pain and fear score was found to be normally distributed among VR users and non-users with skewness and kurtosis score within -20 and 2, therefore the assumption of variable normality was met (Table 2). Additionally, when the tests were compared using normaland not normal distribution the results were same.

Table I Demographic Data of the Children Aged 4-6 Years Old, Including Information on Age, Gender, Pain and Fear Score Between the Two Groups (User and Non-User of VR)

\begin{tabular}{|c|c|c|}
\hline \multirow[t]{3}{*}{ Patient Characteristics } & \multicolumn{2}{|c|}{ Use of VR During Vaccination } \\
\hline & Yes & No \\
\hline & $N=53(50.96 \%)$ & $N=5 I(49.03 \%)$ \\
\hline \multicolumn{3}{|l|}{ Gender, n (\%) } \\
\hline Female & $25(47.16 \%)$ & 25 (49.0I\%) \\
\hline Male & $28(52.83 \%)$ & $26(50.98 \%)$ \\
\hline \multicolumn{3}{|l|}{ Age } \\
\hline Mean \pm SD & $5.38 \pm 0.59$ & $5.18 \pm 0.68$ \\
\hline \multicolumn{3}{|l|}{ Pain score $(0-10)$} \\
\hline Mean \pm SD & $1.36 \pm 2.067$ & $6.90 \pm 3.471$ \\
\hline Range & $(0,8)$ & $(0,10)$ \\
\hline \multicolumn{3}{|l|}{ Fear score (0-5) } \\
\hline Mean \pm SD & $0.64 \pm 0.922$ & $2.88 \pm 1.558$ \\
\hline Range & $(0,3)$ & $(0,4)$ \\
\hline
\end{tabular}


Table 2 Normality Assessment

\begin{tabular}{|c|c|c|c|}
\hline Outcome & Use VR Glasses During Vaccination & Statistics & Value \\
\hline \multirow[t]{8}{*}{ Pain score } & Yes & Mean \pm SD & $1.36 \pm 2.06$ \\
\hline & & Median & 0 \\
\hline & & Skewness & 1.8 \\
\hline & & Kurtosis & 2.9 \\
\hline & No & Mean \pm SD & $6.9 \pm 3.47$ \\
\hline & & Median & 8 \\
\hline & & Skewness & -0.86 \\
\hline & & Kurtosis & -0.64 \\
\hline \multirow[t]{8}{*}{ Fear score } & Yes & Mean \pm SD & $0.64 \pm 0.92$ \\
\hline & & Median & 0 \\
\hline & & Skewness & 1.40 \\
\hline & & Kurtosis & 1.09 \\
\hline & No & Mean \pm SD & $2.88 \pm 1.56$ \\
\hline & & Median & 4 \\
\hline & & Skewness & -1.02 \\
\hline & & Kurtosis & -0.66 \\
\hline
\end{tabular}

Bivariate analysis showed insignificant differences between demographic variables (gender and age), and the pain and fear scores ( $p$-value $>0.5$ ). While, significant differences were reported in pain and fear scores among those vaccinated with or without the VR technology (p-value < 0.001) (Table 3, Figures 1 and 2).

Two linear regression models were applied to test the relationship between the vaccination approach and the pain and fear scores, and showed a negative relationship, taking into account that the other variables (age and gender) were constant. In the first model, pain score was lower by $69 \%$ among children who were vaccinated using the VR technology (p-value $<0.001$ ). In the second model, fear score was $64 \%$ lower in the VR group (p-value $<0.001$ ) (Table 4).

\section{Discussion}

Our primary hypothesis was that going into a computer generated virtual world during venipuncture would reduce fear and pain during immunization among Saudi children aged 4-6 years old. As predicted, overall, the participants who used the VR technology experienced significantly less pain and fear compared with the No VR group. This finding is supported by a previously published study by Chad et al.

Table 3 Bivariate Analysis of the Children Aged 4-6 Years Old

\begin{tabular}{|c|c|c|c|c|c|c|c|c|}
\hline \multirow[t]{2}{*}{ Patient Characteristics } & \multicolumn{4}{|c|}{ Pain Score } & \multicolumn{4}{|c|}{ Fear Score } \\
\hline & Mean \pm SD & Test-value & P-value & $95 \% \mathrm{Cl}$ & Mean \pm SD & Test-value & P-value & $95 \% \mathrm{Cl}$ \\
\hline Age* & $4.08 \pm 3.97$ & -0.137 & 0.165 & $(-0.33,0.06)$ & $1.74 \pm 1.695$ & -0.208 & 0.034 & $(-0.40,-0.02)$ \\
\hline \multicolumn{9}{|l|}{ Gender } \\
\hline Male & $3.67 \pm 4.01$ & -1.096 & 0.276 & $(-2.39,0.69)$ & $1.63 \pm 1.67$ & -0.691 & 0.491 & $(-0.89,0.43)$ \\
\hline Female & $4.52 \pm 3.91$ & & & & $1.86 \pm 1.72$ & & & \\
\hline \multicolumn{9}{|c|}{ Use of VR during vaccination } \\
\hline Yes & $1.36 \pm 2.06$ & -9.93 & 0 & $(-6.65,-4.43)$ & $0.64 \pm 0.922$ & 8.969 & 0 & $(1.74,2.73)$ \\
\hline No & $6.90 \pm 3.47$ & & & & $2.88 \pm 1.558$ & & & \\
\hline
\end{tabular}

Note: *Pearson correlation score. 


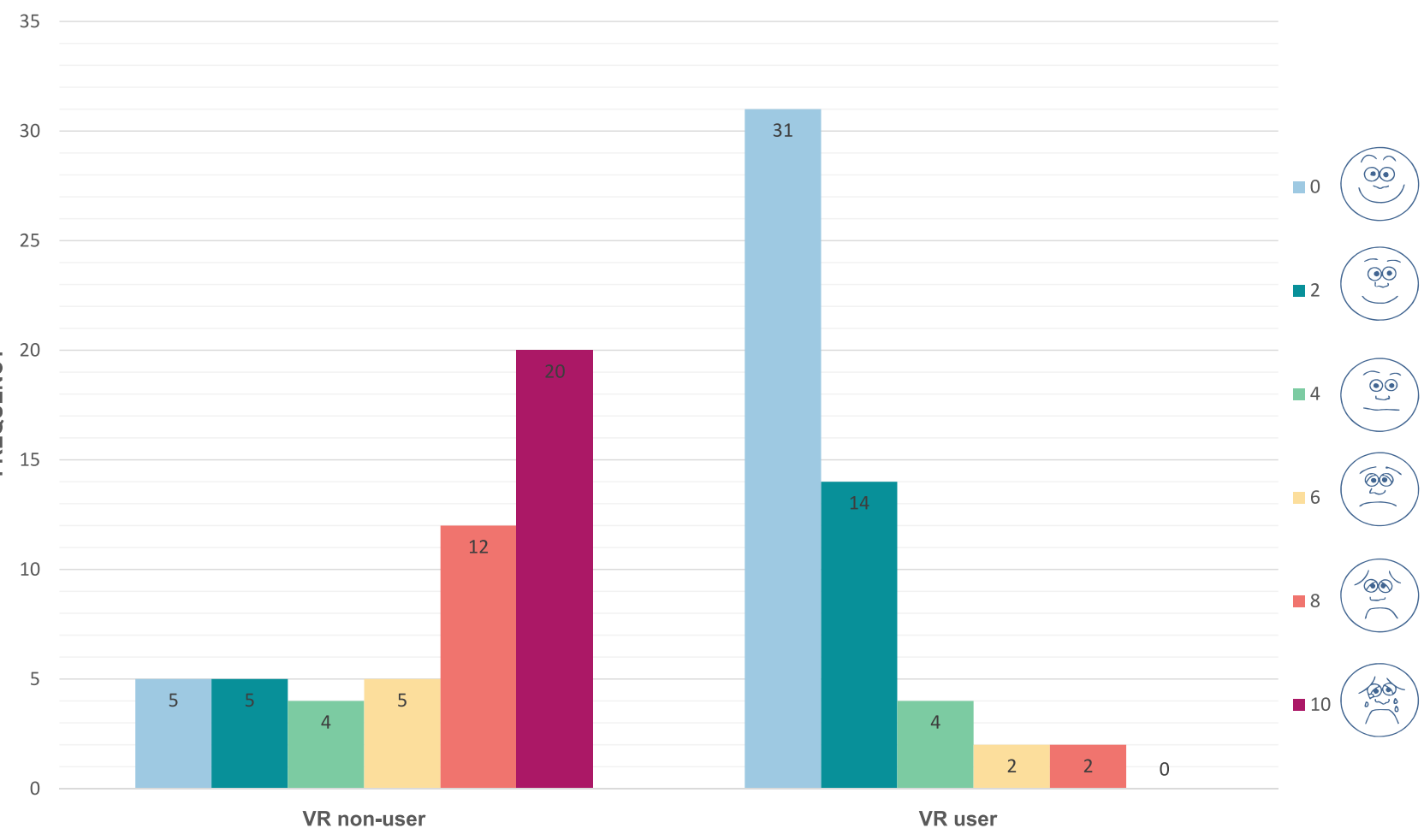

PIAN SCORE

Figure I Comparison of pain scores between the VR non-users and VR users.

Notes: Copyright 1983, Wong-Baker FACES Foundation, www.WongBakerFACES.org. Used with permission." Originally published in Whaley \& Wong's Nursing Care of Infants and Children. (C) Elsevier Inc. ${ }^{15}$

who used a VR headset during immunization and found similar improvements among pediatric subjects, ${ }^{8}$ and adds to a growing literature showing the value of using VR during venipuncture. ${ }^{17,22,23}$ Studies that assess the application of VR in health care have consistently reported the effectiveness of VR as a distraction tool..$^{5,8,10,13,22-30} \mathrm{VR}$ has been used in dental care and to control chronic disease-related pain. ${ }^{26,28}$ VR has also been found to be effective in reducing elderly falls, procedural pain, itching, cerebral palsy patients during painful physical therapy rehabilitation, and for claustrophobic patients during brain scan. ${ }^{12,31}$

The objective of this study was to compare pain and fear scores among children aged 4-6 years old who used or did not use VR as a distraction tool during vaccination. All participants who used the VR technology experienced significantly less pain and fear than non-users. This finding is supported by a previously published study by Chad et al. ${ }^{8}$

There was no evidence of a statistically significant effect of age and gender on pain and fear scores in our study. The same result was found in a randomized controlled clinical trial conducted by Asl Aminabadi et al., ${ }^{24}$ indicating that the measurement of pain and fear was similar among different ages and genders.
Some research suggests that pain and fear concepts are difficult to define among children compared with adults, as older children tend to express their feelings better than younger children. ${ }^{20,28,32}$ Thus, using validated scales is a strength to our study as we found children responded well with facial expressions. A previous study using the same scales, Wong-Baker FACES Pain Scale and the McMurtry Children's Fear Scale, have also reported the usefulness of these measures among children during immunization. ${ }^{8}$

Our study was carried out in a two-month period in one primary healthcare center, that was the only center in the region to approve vaccination using the VR technology, which limits the generalizability of results. Furthermore, the study participants were not randomly grouped, thus a selection bias might have occurred. However, it is the first study in Saudi Arabia that assesses the effectiveness of VR to reduce pain and fear in young children undergoing vaccination. The study included more than 0100 participants, which is more than what is currently reported in the literature. ${ }^{8}$ Results of this study encourage the need for initiatives that decrease fear and pain among children when delivering care. In addition, recent research has shown that increasing the immersiveness of the VR systems makes VR a much more 


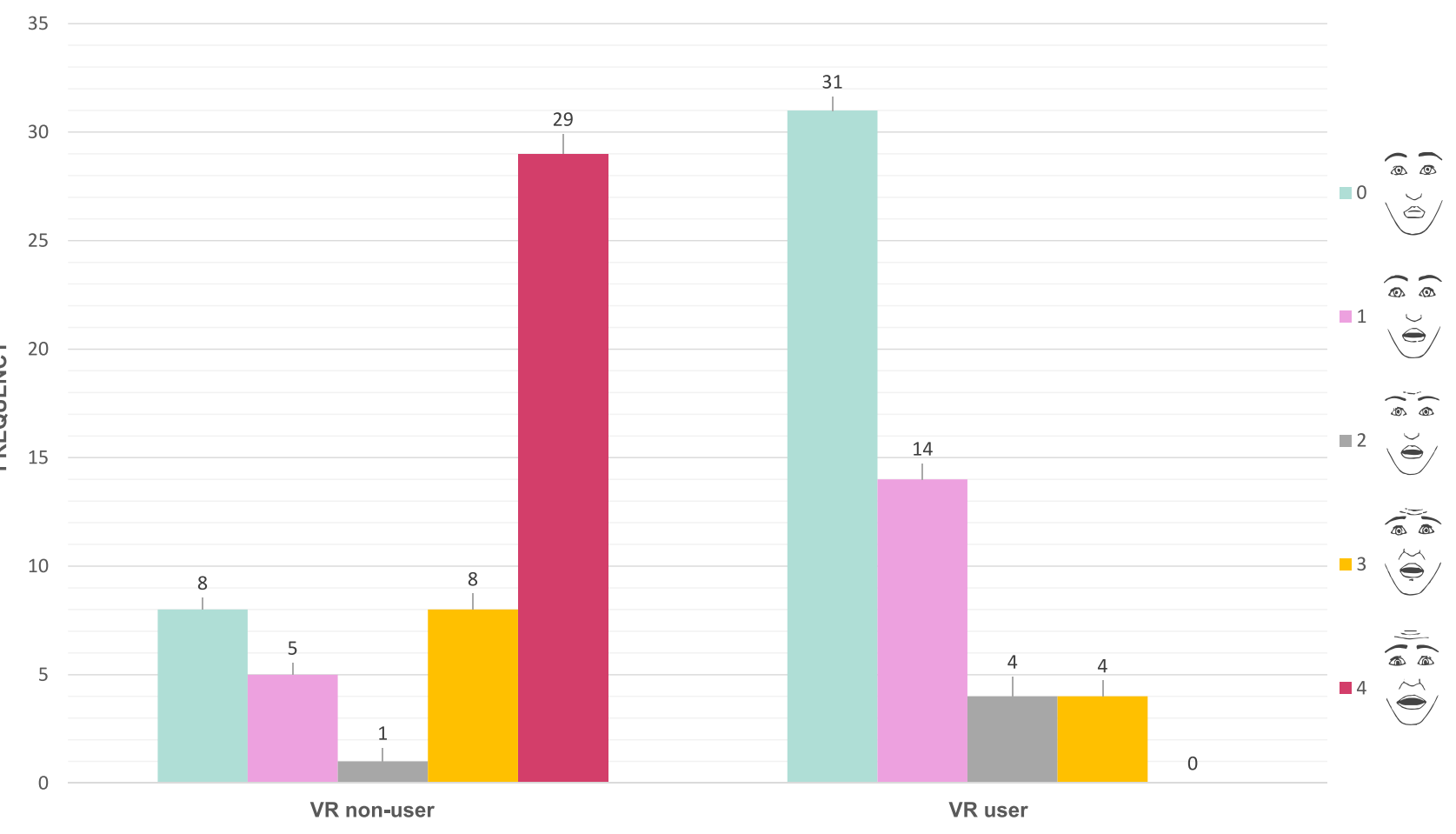

FEAR SCORE

Figure 2 Comparison of fear scores between the VR non-users and VR users.

powerful analgesic. ${ }^{12,33}$ Future studies should consider using more immersive VR systems. The success of using the virtual reality technology in reducing pain and fear could be replicated to all painful procedures related to needle phobia among children.

\section{Conclusion}

The use of virtual reality technology is an emerging technology in pediatric health care. This study found that the use of
VR during vaccination could reduce fear and pain among children. As governments face system challenges in delaying vaccination schedules among children due to the fear from needles, health leaders and policymakers are encouraged to expand the use of this distraction tool to improve the vaccination experience among children in the community.

\section{Disclosure}

The authors report no conflicts of interest in this work.

Table 4 Multivariate Analysis of the Children Aged 4-6 Years Old

\begin{tabular}{|c|c|c|c|c|c|c|}
\hline \multirow[t]{2}{*}{ Characteristics } & \multicolumn{3}{|c|}{ Pain Score } & \multicolumn{3}{|c|}{ Fear Score } \\
\hline & Standardized $\beta$ & p-value & Confidence Interval (95\%) & Standardized $\beta$ & p-value & $\begin{array}{c}\text { Confidence Interval } \\
(95 \%)\end{array}$ \\
\hline Age & -0.032 & 0.658 & $(-1.06,0.67)$ & -0.109 & 0.42 & $(-0.676,0.103)$ \\
\hline \multicolumn{7}{|l|}{ Gender } \\
\hline $\begin{array}{l}\text { Male } \\
\text { Female }\end{array}$ & $\begin{array}{c}\mathrm{I} .00 \text { (ref) } \\
0.76\end{array}$ & 0.177 & $(-0.34,1.86)$ & $\begin{array}{c}\mathrm{I} .00 \text { (ref) } \\
0.06\end{array}$ & 0.147 & $(-0.293,0.696)$ \\
\hline \multicolumn{7}{|c|}{ Use of VR during vaccination } \\
\hline $\begin{array}{l}\text { Yes } \\
\text { No }\end{array}$ & $\begin{array}{c}\text { I.00 (Ref) } \\
9.72\end{array}$ & $<0.001$ & $(4.37,6.61)$ & $\begin{array}{c}\text { I.00 (Ref) } \\
0.65\end{array}$ & $<0.001$ & $(1.68,2.68)$ \\
\hline
\end{tabular}




\section{References}

1. Centers for Disease Control and Prevention. Understanding how vaccines work. Pridobljeno. 2018;1(5):2020.

2. Canouï E, Launay O. Histoire et principes de la vaccination. Rev Mal Respir. 2019;36(1):74-81. doi:10.1016/j.rmr.2018.02.015

3. Immunization - vaccines frequently asked questions [Internet]. Ministry of Health; [cited October 21, 2020]. Available from: https://www.moh.gov.sa/en/HealthAwareness/EducationalContent/vac cination/Pages/Questions.aspx. Accessed August 16, 2021.

4. Ten great public health achievements - United States, 2001-2010 [Internet]. Centers for Disease Control and Prevention; [cited June 29, 2021]. Available from: https://www.cdc.gov/mmwr/pre view $/ \mathrm{mmwrhtml} / \mathrm{mm} 6019 \mathrm{a} 5 . \mathrm{htm}$. Accessed August 16, 2021

5. Arane K, Behboudi A, Goldman RD. Virtual reality for pain and anxiety management in children. Can Fam Physician. 2017;63 (12):932-934.

6. Shukla VV, Shah RC. Vaccinations in primary care. Indian J Pediatr. 2018;85(12):1118-1127. doi:10.1007/s12098-017-2555-2

7. MOH News - MOH launches VR to help kids overcome fear of immunization [Internet]. Ministry of Health; [cited October 21, 2020]. Available from: https://www.moh.gov.sa/en/Ministry/ MediaCenter/News/Pages/News-2018-08-03-0017.aspx. Accessed August 16, 2021.

8. Chad R, Emaan S, Jillian O. Effect of virtual reality headset for pediatric fear and pain distraction during immunization. Pain Manag. 2018;8(3):175-179. doi:10.2217/pmt-2017-0040

9. Birnie KA, Chambers CT, Spellman CM. Mechanisms of distraction in acute pain perception and modulation. Pain. 2017;158 (6):1012-1013. doi:10.1097/j.pain.0000000000000913

10. Khadra C, Ballard A, Déry J, et al. Projector-based virtual reality dome environment for procedural pain and anxiety in young children with burn injuries: a pilot study. J Pain Res. 2018;11:343-353. doi:10.2147/JPR.S151084

11. Guion RM. Assessment, Measurement, and Prediction for Personnel Decisions. Taylor \& Francis; 2011:648.

12. Hoffman HG, Chambers GT, Meyer WJ, et al. Virtual reality as an adjunctive non-pharmacologic analgesic for acute burn pain during medical procedures. Ann Behav Med. 2011;41(2):183-191. doi:10.1007/s12160-010-9248-7

13. Wong CL, Lui MMW, Choi KC. Effects of immersive virtual reality intervention on pain and anxiety among pediatric patients undergoing venipuncture: a study protocol for a randomized controlled trial. Trials. 2019;20(1):1-10. doi:10.1186/s13063-019-3443-Z

14. Chan E, Foster S, Sambell R, Leong P. Clinical efficacy of virtual reality for acute procedural pain management: a systematic review and meta-analysis. PLoS One. 2018;13(7):e0200987. doi:10.1371/ journal.pone.0200987

15. Wong-Baker FACES Foundation. Wong-Baker FACES $®$ Pain Rating Scale. Originally published in Whaley \& Wong's Nursing Care of Infants and Children; (C) Elsevier Inc; 2020 [updated October 21, 2020]. Available from: http://www.WongBakerFACES.org. Accessed August 16, 2021.

16. Wint SS, Eshelman D, Steele J, Guzzetta CE. Effects of distraction using virtual reality glasses during lumbar punctures in adolescents with cancer. Oncol Nurs Forum. 2002;29(1):E8-15. doi:10.1188/02. ONF.E8-E15
17. Gold JI, Mahrer NE. Is virtual reality ready for prime time in the medical space? A randomized control trial of pediatric virtual reality for acute procedural pain management. J Pediatr Psychol. 2018;43 (3):266-275. doi:10.1093/jpepsy/jsx129

18. Ellerton K, Tharmarajah H, Medres R, et al. The VRIMM study: Virtual Reality for IMMunisation pain in young children - protocol for a randomised controlled trial. BMJ Open. 2020;10(8):e038354. doi:10.1136/bmjopen-2020-038354

19. Taddio A, Chambers CT, Halperin SA, et al. Inadequate pain management during routine childhood immunizations: the nerve of it. Clin Ther. 2009;31:S152-67. doi:10.1016/j.clinthera.2009.07.022

20. McMurtry CM, Noel M, Chambers CT, McGrath PJ. Children's fear during procedural pain: preliminary investigation of the Children's Fear Scale. Health Psychol. 2011;30(6):780-788. doi:10.1037/a0024817

21. Hockenberry MJ, Wilson D. Wong's Nursing Care of Infants and Children-E-Book. Elsevier Health Sciences; 2018.

22. Atzori B, Hoffman HG, Vagnoli L, et al. Virtual reality analgesia during venipuncture in pediatric patients with onco-hematological diseases. Front Psychol. 2018;9:2508. doi:10.3389/fpsyg.2018.02508

23. Atzori B, Lauro Grotto R, Giugni A, Calabrò M, Alhalabi W, Hoffman HG. Virtual reality analgesia for pediatric dental patients. Front Psychol. 2018;9:2265. doi:10.3389/fpsyg.2018.02265

24. Asl Aminabadi N, Erfanparast L, Sohrabi A, Ghertasi Oskouei S, Naghili A. The impact of virtual reality distraction on pain and anxiety during dental treatment in 4-6 year-old children: a Randomized Controlled Clinical Trial. J Dent Res Dent Clin Dent Prospects. 2012;6(4):117-124.

25. Kurup L, He H-G, Wang X, Wang W, Shorey S. A descriptive qualitative study of perceptions of parents on their child's vaccination. J Clin Nurs. 2017;26(23-24):4857-4867. doi:10.1111/jocn.13958

26. Franck LS, Berberich FR, Taddio A. Parent participation in a childhood immunization pain reduction method. Clin Pediatr (Phila). 2015;54(3):228-235. doi:10.1177/0009922814561593

27. Jones T, Moore T, Choo J. The impact of virtual reality on chronic pain. PLoS One. 2016;11(12):e0167523. doi:10.1371/journal. pone. 0167523

28. Piskorz J, Czub M. Effectiveness of a virtual reality intervention to minimize pediatric stress and pain intensity during venipuncture. J Spec Pediatr Nurs. 2018;23(1):e12201. doi:10.1111/jspn.12201

29. Won AS, Bailey J, Bailenson J, Tataru C, Yoon IA, Golianu B. Immersive virtual reality for pediatric pain. Children. 2017;4(7):52. doi:10.3390/children4070052

30. Nilsson S, Finnström B, Kokinsky E, Enskär K. The use of virtual reality for needle-related procedural pain and distress in children and adolescents in a paediatric oncology unit. Eur J Oncol Nurs. 2009;13 (2):102-109. doi:10.1016/j.ejon.2009.01.003

31. Duque G, Boersma D, Loza-Diaz G, et al. Effects of balance training using a virtual-reality system in older fallers. Clin Interv Aging. 2013;8:257. doi:10.2147/CIA.S41453

32. Pillitteri A. Maternal \& Child Health Nursing: Care of the Childbearing \& Childrearing Family. Lippincott Williams \& Wilkins; 2010.

33. Al-Ghamdi NA, Meyer WJ III, Atzori B, et al. Virtual reality analgesia with interactive eye tracking during brief thermal pain stimuli: a randomized controlled trial (crossover design). Front Hum Neurosci. 2020;13:467. doi:10.3389/fnhum.2019.00467 


\section{Publish your work in this journal}

The Journal of Multidisciplinary Healthcare is an international, peerreviewed open-access journal that aims to represent and publish research in healthcare areas delivered by practitioners of different disciplines. This includes studies and reviews conducted by multidisciplinary teams as well as research which evaluates the results or conduct of such teams or healthcare processes in general. The journal covers a very wide range of areas and welcomes submissions from practitioners at all levels, from all over the world. The manuscript management system is completely online and includes a very quick and fair peer-review system. Visit http://www.dovepress.com/testimonials. php to read real quotes from published authors. 